\title{
PENGARUH DIMENSI KOMPOR DAN KADAR AIR BIOMASSA TERHADAP KINERJA KOMPOR GASIFIKASI FORCED DRAFT
}

\author{
Zulfansyah*, Hermanto, Muhammad Iwan Fermi \\ Laboratorium Pengendalian dan Perancangan Proses \\ Jurusan Teknik Kimia, Fakultas Teknik, Universitas Riau \\ Kampus Binawidya Km. 12,5 Sp. Baru, Pekanbaru 28293 \\ Email: zulfansyah@unri.ac.id
}

\begin{abstract}
Abstrak
Tingkat penggunaan biomassa sebagai sumber energi primer di Indonesia cukup tinggi yaitu mencapai 280 juta setara barel minyak (SBM) dan sekitar 84\% dari biomassa tersebut digunakan untuk kebutuhan sektor rumah tangga. Penggunaan kompor gasifikasi untuk kebutuhan rumah tangga khususnya untuk kegiatan memasak dapat meningkatkan efisiensi penggunaan bahan bakar. Pada penelitian ini digunakan tiga unit kompor gasifikasi dengan variasi dimensi ruang bakar kompor. Sedangkan bahan bakar yang digunakan yaitu ranting kayu akasia dengan kadar air 7,26\%, 9,63\% dan 12,58\%. Metoda pengujian mengikuti prosedur water boiling test (WBT), selain itu waktu operasi dan temperatur nyala api juga menjadi parameter kinerja kompor gasifikasi yang dievaluasi. Efisiensi termal kompor gasifikasi forced draft yang dihasilkan yaitu 25,03\% hingga 30,44\%, dengan efisiensi tertinggi yaitu pada kompor berdiameter $12 \mathrm{~cm}$ dan tinggi $16 \mathrm{~cm}$ serta biomassa berkadar air $9,63 \%$. Walaupun nyala api yang dihasilkan masih berwarna kuning kemerahan, namun kompor gasifikasi forced draft mampu menghasilkan energi termal hingga 3,43 kWth (kilowatt thermal) dengan temperatur nyala api tertinggi mencapai $933^{\circ} \mathrm{C}$. Hasil penelitian menunjukkan bahwa kondisi operasi kompor gasifikasi sangat berpengaruh terhadap kinerja kompor sehingga disain kondisi operasi kompor perlu disesuaikan dengan kebutuhan pengguna kompor gasifikasi.
\end{abstract}

Keywords: biomassa, kompor gasifikasi, forced draft, efisiensi termal

\begin{abstract}
INFLUENCE OF STOVE DIMENSIONS AND BIOMASS MOISTURE CONTENT ON FORCED DRAFT GASIFICATION STOVE PERFORMANCE. Consumption level of biomass as a source of primary energy in Indonesia is quite high, reaching 280 million barrels of oil equivalent (BOE) and approximately $84 \%$ of the biomass is has been used for the household sector. The application of gasification stove especially in cooking purposes can increase the efficiency of fuel usage. This research uses three units gasification stove with variation of stove dimension. Acacia wood branches with moisture content 7.26\%, 9.63\% and $12.58 \%$ were used as fuel source. Water boiling test (WBT) procedural was used to evaluate the stove performance. Operating time and flame temperature of the stove also were the parameter of stove performance evaluation. Thermal efficiency of the forced draft gasification stove is approximately $25.03 \%$ to $30.44 \%$, the most efficient is $12 \mathrm{~cm}$ in diameter and $16 \mathrm{~cm}$ high stove with $9.63 \%$ biomass moisture content. Although the resulting flame is still reddish yellow, the forced draft gasification stove is capable of producing up to $3.43 \mathrm{kWth}$ (kilowatt thermal) thermal energy with the highest flame temperature reaches $933{ }^{\circ} \mathrm{C}$. The results show that the gasification stove operating conditions greatly affect the performance of the stove.
\end{abstract}

Kata kunci: biomass, gasification stove, forced draft, thermal efficiency

*penulis korespondensi 


\section{PENDAHULUAN}

Biomassa merupakan sumber energi yang jumlahnya banyak tersedia di alam, sehingga berpotensi untuk dikembangkan menjadi sumber energi alternatif pengganti energi fosil. Biomassa di Indonesia sebagian besar berasal dari pertanian dan perkebunan, yaitu mencapai $85 \%$ dan sisanya berasal dari hutan (Dewi, 2010). Ketersediaan biomassa sebagai sumber energi primer di Indonesia mencapai 280 juta Setara Barel Minyak (SBM) dan sekitar 84\% dari biomassa tersebut digunakan untuk kebutuhan sektor rumah tangga (ESDM, 2010).

Kompor gasifikasi adalah salah satu teknologi pemanfaatan biomassa yang dapat digunakan untuk kebutuhan memasak pada sektor rumah tangga. Gasifikasi merupakan proses konversi bahan bakar padat secara termo-kimia menjadi gas mudah terbakar, yang terdiri dari karbonmonoksida (CO), hidrogen $\left(\mathrm{H}_{2}\right)$ dan metana $\left(\mathrm{CH}_{4}\right)$ (Rajvanshi, 1986). Konversi biomassa menjadi energi termal menggunakan kompor gasifikasi dapat meningkatkan efisiensi termal hingga dua kali lipat dari pembakaran biomassa secara konvensional (Panwar, 2009).

Sistem pasokan udara kompor gasifikasi dibedakan menjadi natural draft dan forced draft. Pada kompor natural draft, pasokan udara yang minim menyebabkan pembakaran kurang sempurna. Sedangkan pada kompor gasifikasi forced draft, pasokan udara sudah mencukupi untuk menghasilkan pembakaran yang lebih sempurna. Dengan demikian, kompor gasifikasi tipe forced draft emisinya lebih rendah dan efisiensi termal lebih tinggi. Efisiensi termal untuk kompor forced draft mencapai 50\% (Mukunda dkk., 2010), sedangkan efisiensi termal untuk kompor natural draft sekitar 35\% (Panwar, 2009). Kelebihan lain dari kompor forced draft, yaitu dapat menggunakan berbagai jenis dan variasi ukuran biomassa karena memiliki kemampuan untuk mengatasi hilang tekan (Reed dkk., 2000).

Faktor lain yang berpengaruh terhadap kinerja kompor gasifikasi adalah dimensi ruang bakar yang meliputi tinggi dan diameter ruang bakar. Semakin besar diameter ruang bakar maka panas dan efisiensi termal yang dihasilkan akan semakin besar. Kompor gasifikasi dengan diameter ruang bakar $32 \mathrm{~cm}$ memiliki efisiensi termal hingga $50 \%$, sedangkan penggunaan kompor dengan ruang bakar berdiameter $26 \mathrm{~cm}$ hanya menghasilkan efisiensi termal 45\% (Mukunda dkk., 2010). Sementara itu, tinggi ruang bakar pada kompor berpengaruh terhadap lama proses gasifikasi. Semakin tinggi reaktor maka semakin lama waktu kompor beroperasi (Belonio, 2005). Pengaruh tinggi ruang bakar hanya terjadi pada kompor dengan sistem batch karena pada kompor jenis ini tinggi unggun bahan bakar akan terus berkurang selama proses gasifikasi.

Kinerja kompor terbaik didapatkan dari optimalisasi dimensi kompor gasifikasi, laju alir udara dan kondisi bahan bakar. Namun demikian penelitian tentang pengaruh dimensi kompor gasifikasi forced draft terhadap kinerja kompor belum banyak dilakukan. Untuk itu, penelitian ini bertujuan mempelajari pengaruh variasi dimensi kompor dan bahan bakar terhadap kinerja kompor gasifikasi forced draft. Dengan hasilhasil penelitian ini, pemanfaatan biomassa dengan kompor gasifikasi sebagai sumber energi alternatif terbarukan dan ramah lingkungan untuk keperluan memasak diharapkan dapat ditingkatkan.

\section{METODE}

Ranting kayu akasia digunakan sebagai bahan bakar pada evaluasi kinerja kompor gasifikasi forced draft dengan panjang $\pm 4 \mathrm{~cm}$. Bahan bakar yang akan digunakan terlebih dahulu dikeringkan di bawah sinar matahari untuk mengurangi kadar airnya hingga mencapai kadar air yang diinginkan. Rangkaian alat yang percobaan evaluasi kinerja kompor gasifikasi dapat dilihat pada Gambar 1.

Variasi variabel percobaan pada penelitian evaluasi kinerja kompor gasifikasi forced draft adalah dimensi ruang bakar dan kadar air biomassa sebagai bahan bakar. Dimensi tersebut meliputi diameter (D) dan tinggi $(\mathrm{H})$. Kompor gasifikasi yang digunakan yaitu Kompor 1 dengan $\mathrm{D}_{1}=10 \mathrm{~cm}$ dan $\mathrm{H}_{1}=$ $16 \mathrm{~cm}$, Kompor 2 dengan $\mathrm{D}_{2}=12 \mathrm{~cm}$ dan $\mathrm{H}_{2}=$ $16 \mathrm{~cm}$ serta Kompor 3 dengan $\mathrm{D}_{3}=12 \mathrm{~cm}$ dan $\mathrm{H}_{3}=20 \mathrm{~cm}$. Kadar air kayu akasia sebagai bahan bakar juga divariasikan, yaitu pada nilai sekitar 7,5\%, 10\%, dan 12,5 \%-berat.

Evaluasi kinerja kompor gasifikasi mengikuti prosedur water boling test (WBT) (Bailis dkk., 2007; Yuntenwi dkk., 2008). Prosedur WBT terdiri dari 3 tahapan yaitu tahap hot start, cold start, dan simmering. Selain prosedur WBT, pada penelitian ini juga dilakukan pengukuran temperatur nyala api 
Pengaruh Dimensi Kompor dan Kadar Air Biomassa (Zulfansyah, dkk.)

dan lama operasi kompor gasifikasi yang diberi umpan biomassa secara batch. Pengukuran temperatur nyala api dilakukan pada bagian tengah nyala api menggunakan termokopel tipe K. Kinerja kompor gasifikasi dapat dilihat dari beberapa parameter seperti waktu startup, laju pembakaran, fire power, dan efisiensi termal. Skema percobaan water boiling test dapat dilihat pada Gambar 2.

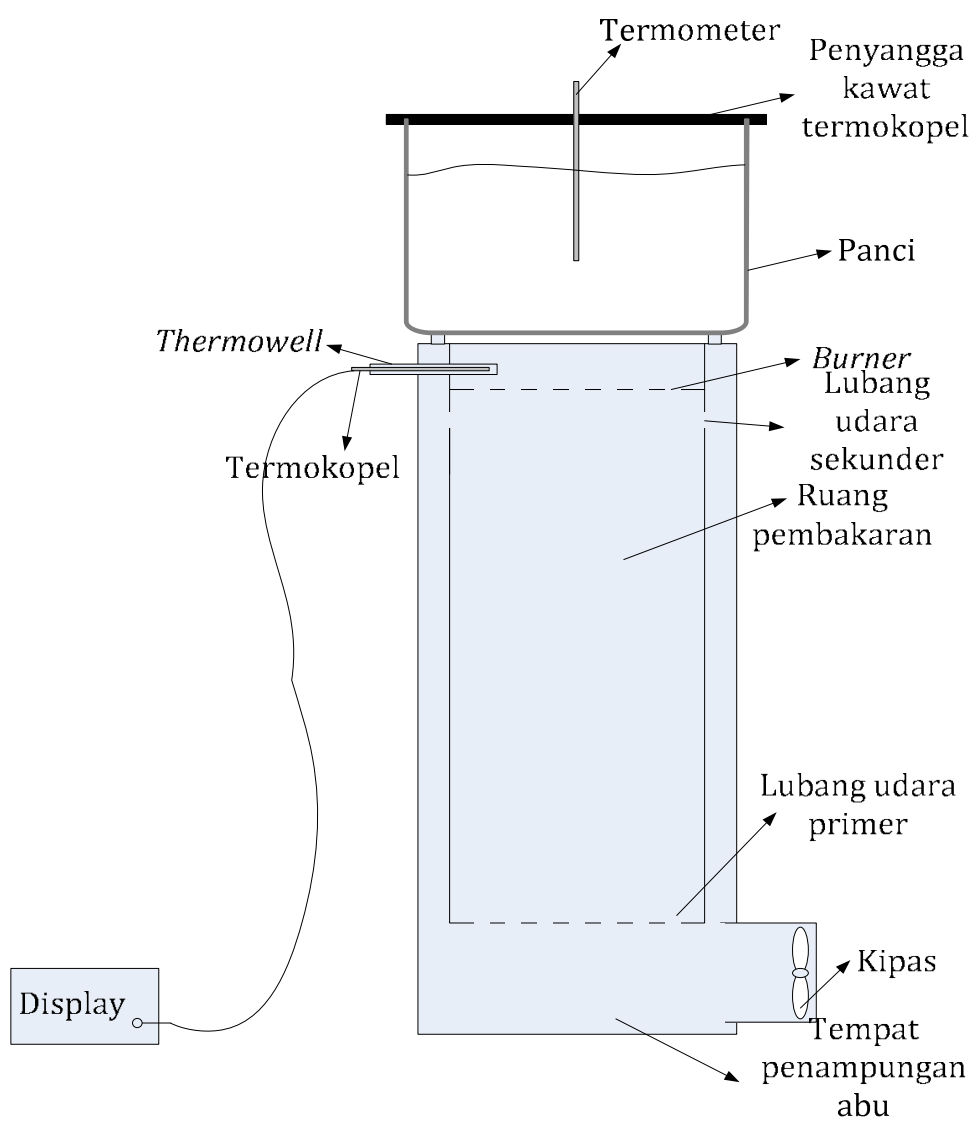

Gambar 1. Rangkaian alat percobaan kompor gasifikasi

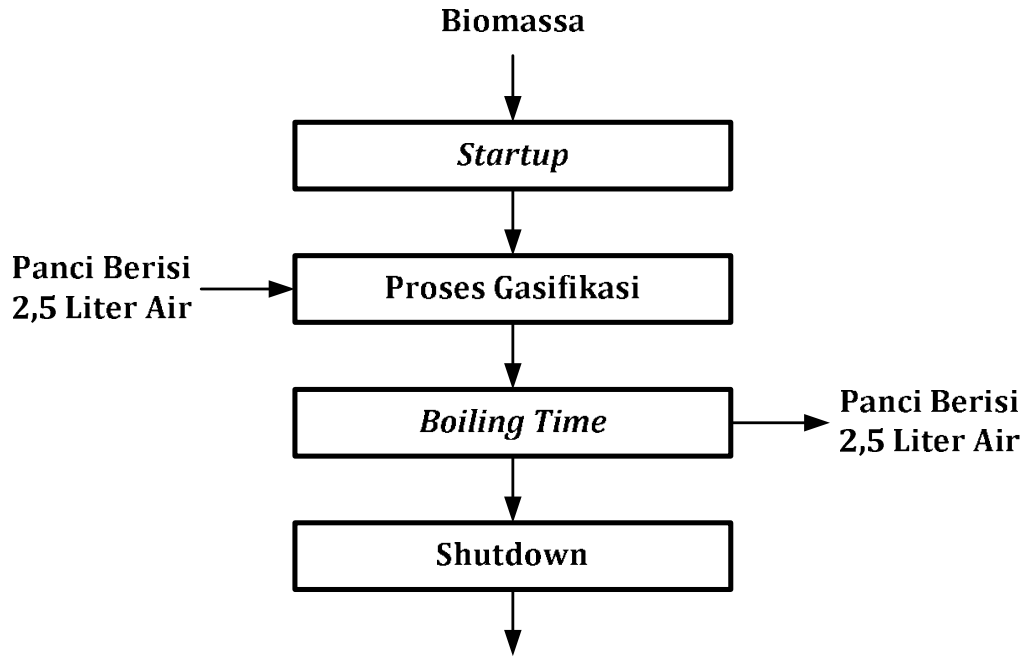

Biomassa Sisa, Arang dan Abu

Gambar 2. Skema percobaan water boiling test 


\section{HASIL DAN PEMBAHASAN}

Percobaan evaluasi kinerja kompor gasifikasi forced draft menunjukkan hasil yang meliputi temperatur nyala api, waktu startup, waktu operasi, laju konsumsi bahan bakar, efisiensi termal, dan fire power. Kompor gasifikasi pada penelitian ini yaitu kompor forced draft dengan aliran udara bersumber dari kipas berarus 0,12 Ampere dan tegangan 12 Volt, dengan listrik dipasok dari adaptor yang telah terhubung ke jaringan listrik PLN. Ranting kayu akasia yang digunakan sebagai bahan bakar kompor gasifikasi terlebih dahulu dipotong-potong dan dikeringkan hingga kadar air tertentu. Densitas unggun untuk ranting kayu akasia dengan kadar air berbeda dapat dilihat pada Tabel 1 .

Tabel 1. Densitas Unggun untuk Variasi Kadar Air Biomassa

\begin{tabular}{ccc}
\hline No. & Kadar Air & $\begin{array}{c}\text { Densitas Unggun } \\
\left(\mathrm{gram} / \mathrm{cm}^{3} \text { ) }\right.\end{array}$ \\
\hline 1 & $12,58 \%$ & 0,281 \\
2 & $9,63 \%$ & 0,260 \\
3 & $7,26 \%$ & 0,249 \\
\hline
\end{tabular}

Evaluasi kinerja gasifikasi forced draft

Percobaan evaluasi kinerja kompor gasifikasi mengikuti prosedur water boiling test (Bailis dkk., 2007). Temperatur nyala api pada percobaan ini berkisar antara $894^{\circ} \mathrm{C}$ sampai dengan $933{ }^{\circ} \mathrm{C}$. Temperatur tertinggi dihasilkan dari kompor 2 dengan bahan bakar berkadar air 7,26\%. Temperatur kompor menunjukkan bahwa proses gasifikasi sudah terjadi karena berdasarkan literatur temperatur gasifikasi berlangsung diatas 800 ${ }^{\circ} \mathrm{C}$ (Higman dan van der Burgt, 2011). Namun nyala api yang dihasilkan dari kompor gasifikasi masih berwarna kuning kemerahan. Nyala api yang kuning kemerahan terjadi karena proses gasifikasi masih belum berjalan dengan sempurna. Hal ini terjadi karena pencampuran udara dan bahan masih kurang baik.

\section{Waktu startup}

Densitas unggun dapat mempengaruhi waktu startup kompor gasifikasi. Semakin rendah densitas unggun bahan bakar maka semakin singkat waktu startup (Yuntenwi dkk., 2008). Densitas unggun identik dengan kadar air biomassa yang digunakan sebagai bahan bakar. Selain itu, diameter kompor gasifikasi juga berpengaruh terhadap waktu startup. Diameter yang kecil menghasilkan luas areal pembakaran yang besar dan biomassa akan lebih mudah terbakar. Grafik pengaruh dimensi kompor dan kadar air biomassa terhadap waktu startup dapat dilihat pada Gambar 3 dan Gambar 4.

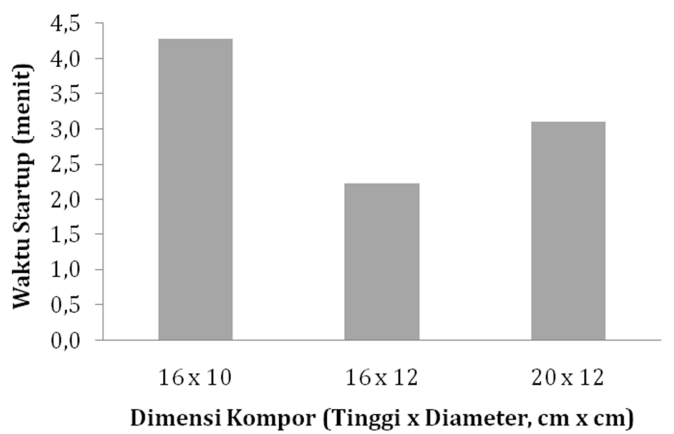

Gambar 3. Pengaruh dimensi kompor terhadap waktu startup

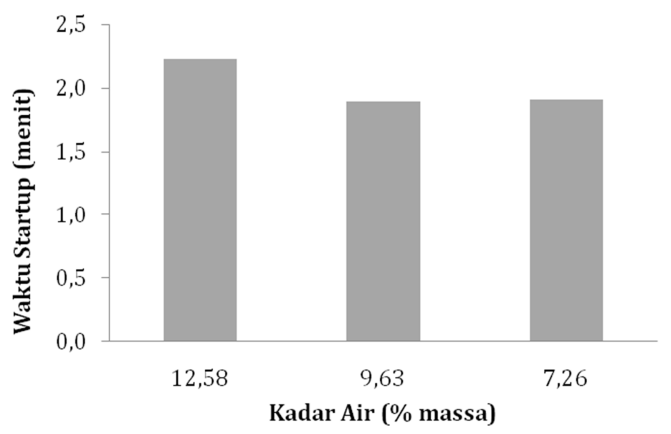

Gambar 4. Pengaruh kadar air biomassa terhadap waktu startup

Kompor gasifikasi dengan diameter 10 cm membutuhkan waktu startup lebih lama yaitu mencapai 4,36 menit jika dibandingkan dengan kompor berdiameter $12 \mathrm{~cm}$ yang hanya 2,84 menit, sedangkan tinggi dari ruang bakar kompor tidak terlalu berpengaruh terhadap waktu startup kompor. Bahan bakar dengan kadar air 12,58\% lebih sulit untuk dinyalakan, sehingga waktu startup yang dibutuhkan mencapai 2,84 menit. Hal ini terjadi karena semakin banyak kadar air biomassa maka akan semakin besar energi yang dibutuhkan untuk menguapkan air dalam biomassa hingga bahan bakar bereaksi pada reaksi pembakaran.

\section{Waktu operasi}

Waktu operasi kompor dapat dipengaruhi oleh dimensi kompor dan kadar air bahan bakar. Semakin tinggi ruang bakar kompor maka akan semakin lama kompor dapat beroperasi. Namun hal ini hanya berlaku untuk kompor dengan sistem 
pembakaran batch (Umogbai dan Orkuma, 2011). Pengaruh dimensi kompor terhadap waktu operasi dapat dilihat pada Gambar 5. Selain itu, kadar air bahan bakar juga mempengaruhi lama operasi kompor. Grafik pengaruh kadar air biomassa terhadap waktu operasi dapat dilihat pada Gambar 6.

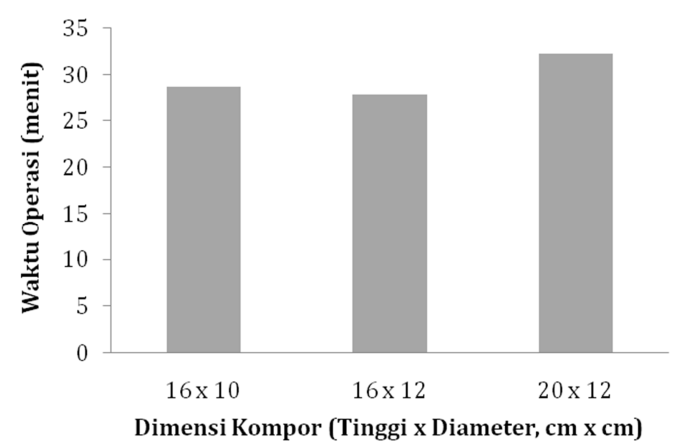

Gambar 5. Pengaruh dimensi kompor terhadap waktu operasi

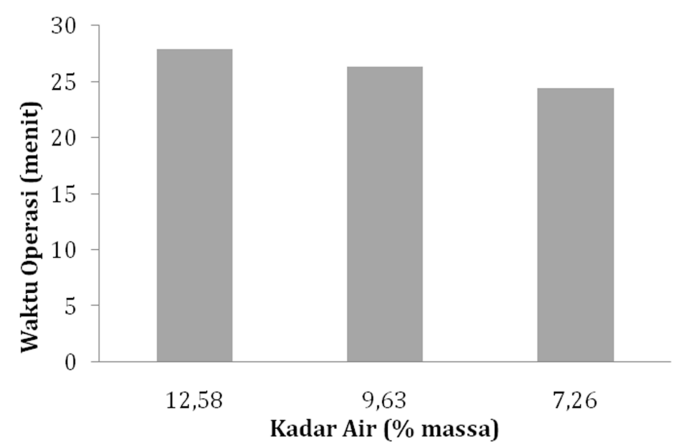

Gambar 6. Pengaruh kadar air biomassa terhadap waktu operasi

Pengaruh tinggi kompor gasifikasi terhadap waktu operasi tampak dari waktu operasi kompor 2 dengan tinggi $16 \mathrm{~cm}$ yang hanya mencapai 27,9 menit. Sedangkan pada kompor 3 dengan tinggi $20 \mathrm{~cm}$, kompor dapat menyala hingga 32,23 menit. Hal ini terjadi karena semakin tinggi ruang pembakaran kompor maka semakin banyak jumlah biomassa yang dapat diumpankan dalam satu batch (Ariho dkk., 2011). Selain itu, kadar air bahan bakar yang semakin kecil memudahkan biomassa bereaksi dengan udara dan kemudian terbakar. Kompor dengan biomassa berkadar air 7,26\% hanya mampu beroperasi selama 24,41 menit, sedangkan penggunaan biomassa berkadar air 12,58\% mampu menghasilkan nyala api selama 27,9 menit.

\section{Fire power}

Luas penampang ruang bakar dapat mempengaruhi fire power yang dihasilkan kompor gasifikasi. Luas penampang dapat ditinjau dari diameter kompor gasifikasi. Semakin besar diameter kompor maka akan semakin besar pula daya yang dihasilkan. Hal ini terjadi karena semakin banyak biomassa yang terbakar pada waktu bersamaan dan menghasilkan nyala api yang lebih besar. Adapun pengaruh dimensi kompor gasifikasi terhadap fire power yang dihasilkan dapat dilihat pada Gambar 7. Fire power terbesar dihasilkan dari Kompor 2 yang berdiameter $12 \mathrm{~cm}$, yaitu mencapai 3,16 kWth (kilowatt thermal). Sedangkan fire power terkecil dihasilkan dari Kompor 1 yang berdiameter $10 \mathrm{~cm}$ yaitu hanya mencapai $2,37 \mathrm{kWth}$.

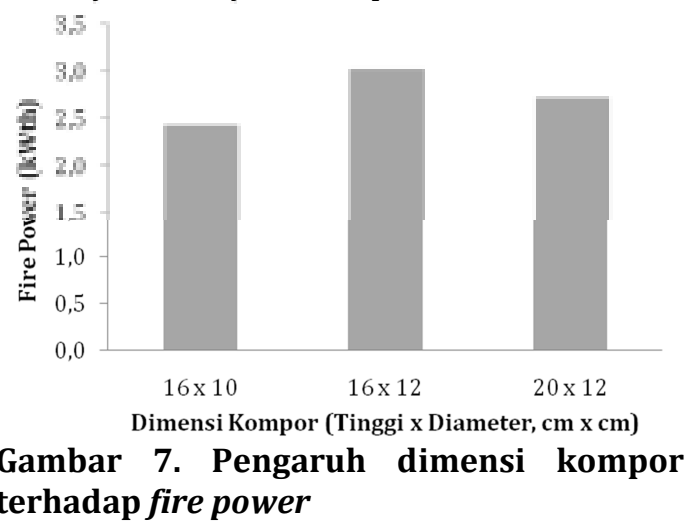

Selain itu, fire power juga dapat dipengaruhi oleh kadar air bahan bakar. Dari hasil percobaan diketahui bahwa semakin besar kadar air bahan bakar maka fire power yang dihasilkan cenderung menurun. Hal ini terjadi karena pada proses gasifikasi dibutuhkan $\mathrm{H}_{2} \mathrm{O}$ pada kadar tertentu untuk menghasilkan gas $\mathrm{H}_{2}$ pada reaksi pertukaran air-gas dan reaksi uap-karbon. Gas $\mathrm{H}_{2}$ memiliki nilai kalor lebih besar jika dibandingkan biomassa ataupun gas mudah terbakar lain yang dihasilkan kompor gasifikasi. Dengan demikian, semakin banyak jumlah gas $\mathrm{H}_{2}$ yang dihasilkan maka akan semakin besar pula fire power kompor (Reed dan Larson, 1996). Pengaruh kadar air terhadap fire power kompor dapat dilihat pada Gambar 8.

Fire power terbesar dihasilkan dari kompor gasifikasi dengan bahan bakar berkadar air 7,26\% yaitu mencapai 3,43 kWth. Sedangkan fire power terkecil dihasilkan pada penggunaan biomassa berkadar air 9,63\% sebagai bahan bakar. 


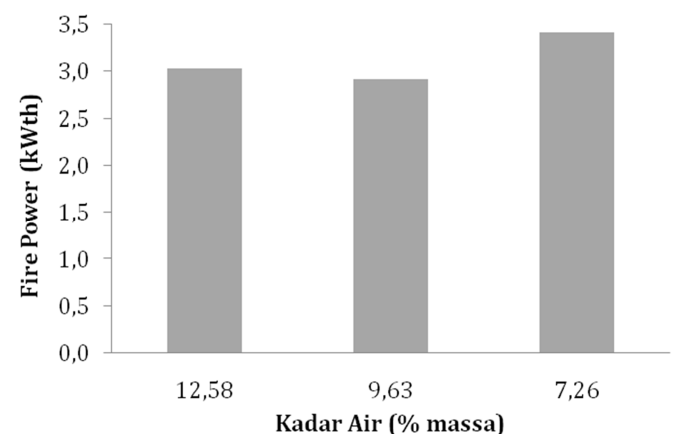

Gambar 8. Pengaruh kadar air biomassa terhadap fire power

\section{Efisiensi termal}

Efisiensi termal kompor gasifikasi menggambarkan seberapa besar energi biomassa yang dapat terkonversi oleh kompor menjadi energi termal dalam bentuk nyala api. Pada percobaan ini digunakan 2,5 L air sebagai media transfer panas. Efisiensi termal dapat dipengaruhi oleh berbagai faktor seperti dimensi kompor dan kadar air biomassa. Grafik pengaruh dimensi kompor dan kadar air biomassa terhadap efisiensi termal kompor gasifikasi dapat dilihat pada Gambar 9 dan Gambar 10. Efisiensi termal tertinggi dihasilkan pada Kompor 2 yaitu mencapai 29,59\%. Sedangkan efisiensi terendah dihasilkan dari Kompor 3 yang hanya mencapai $25.03 \%$.

Pengaruh kadar air biomassa terhadap efisiensi termal tidak terlalu signifikan. Efisiensi termal tertinggi diperoleh dari kompor gasifikasi dengan kadar air 9,63\% yaitu mencapai 30,44\%. Sedangkan efisiensi terendah diperoleh dari pembakaran biomassa berkadar air 7,26\% yang hanya mencapai 25,24\%. Efisiensi termal yang rendah dihasilkan oleh proses gasifikasi yang kurang sempurna, sehingga untuk mendapatkan efisiensi tertinggi dibutuhkan kadar air yang tepat untuk reaksi-reaksi pada proses gasifikasi.

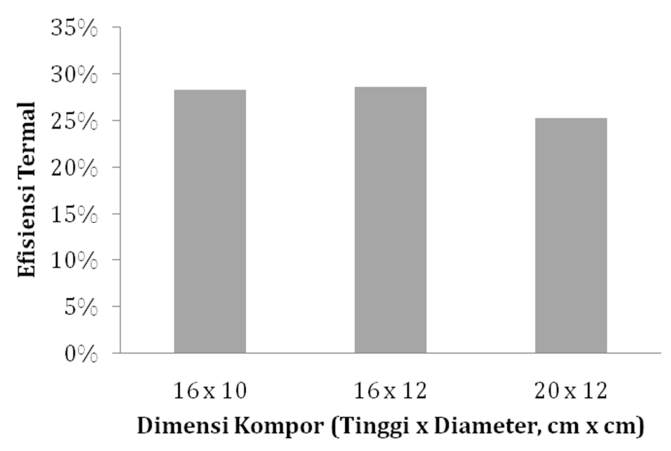

Gambar 9. Pengaruh dimensi kompor terhadap efisiensi termal.

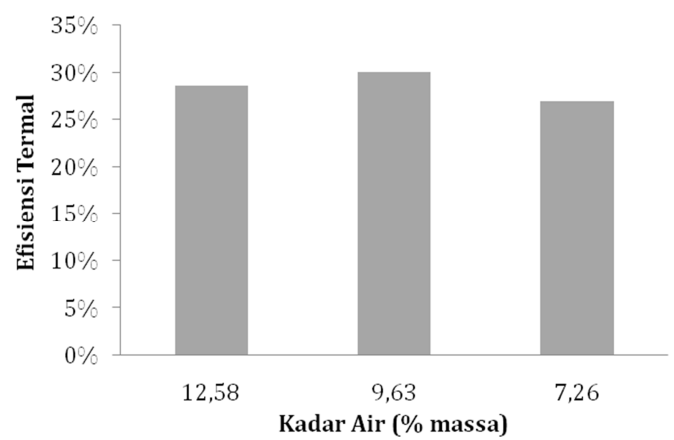

Gambar 10. Pengaruh kadar air biomassa terhadap efisiensi termal

Perbandingan hasil penelitian dengan penelitian sebelumnya

Tingkat perbandingan hasil penelitian evaluasi kinerja kompor gasifikasi ini dengan hasil penelitian yang pernah dilakukan oleh para peneliti lain dapat dilihat pada Tabel 2 . Jika dibandingkan dengan penelitian lain, kinerja kompor gasifikasi pada penelitian ini tidak jauh berbeda dari kompor forced draft lain dan bahkan cenderung lebih baik. Nilai tersebut dilihat dari waktu startup dan fire power yang dihasilkan oleh kompor. Sedangkan jika dibandingkan penelitian kompor natural draft (Ariho dkk., 2011), kinerja kompor forced draft ini jauh lebih baik.

Tabel 2. Perbandingan Hasil Penelitian Kompor Gasifikasi

\begin{tabular}{|c|c|c|c|c|c|}
\hline No. & Parameter & $\begin{array}{l}\text { Ariho dkk. } \\
\quad 2011\end{array}$ & $\begin{array}{l}\text { Reed dkk. } \\
\quad 2000\end{array}$ & $\begin{array}{l}\text { Mukunda dkk. } \\
2010 \\
\end{array}$ & $\begin{array}{l}\text { Penelitian } \\
\text { ini }\end{array}$ \\
\hline 1 & Startup (menit) & $1-23$ & $1-5$ & 2 & $1,5-4,5$ \\
\hline 2 & $\begin{array}{l}\text { Laju Konsumsi bahan } \\
\text { bakar (gram/menit) }\end{array}$ & $1-11$ & 10 & 12 & $8-11,5$ \\
\hline 3 & Efisiensi termal (\%) & $12-19$ & $24-39$ & $49-53$ & $25-30$ \\
\hline 4 & Fire power (kWth) & - & 2,5 & $2-5$ & $2,5-3,5$ \\
\hline
\end{tabular}




\section{KESIMPULAN}

Dimensi kompor sangat berpengaruh terhadap lama waktu operasi dan fire power yang dihasilkan. Waktu operasi terlama dengan fire power terbesar dihasilkan dari kompor 3 yang berdiameter $12 \mathrm{~cm}$ dan tinggi $20 \mathrm{~cm}$. Sedangkan kadar air biomassa sangat berpengaruh terhadap waktu startup dan waktu operasi kompor.

Efisiensi termal tertinggi pada kompor forced draft mencapai 30,44\% yang dihasilkan dari kompor 2 dengan bahan berkadar air 9,63\%. Hasil penelitian menunjukkan bahwa kondisi operasi kompor gasifikasi sangat berpengaruh terhadap kinerja kompor sehingga disain kondisi operasi kompor perlu disesuaikan dengan kebutuhan pengguna kompor gasifikasi.

\section{UCAPAN TERIMA KASIH}

Terimakasih kepada Lembaga Penelitian Universitas Riau yang telah memberikan dana, melalui program Penelitian Laboratorium Universitas Riau Tahun 2012.

\section{DAFTAR PUSTAKA}

Ariho, D.; Tumutegyereize, P.; Bechtel, K., Evaluation of energy efficiencies of commonly available biomass fuels in Uganda in a "Champion-2008" Top Lit Updraft gasifier stove, 2011, http://www.bioenergylist.org (akses 7 April 2011).

Bailis, R.; Ogle, D.; MacCarty, N.; Smith, K. R.; Edwards, R., The Water Boiling Test, 2007, http://ehs.sph.berkeley.edu (akses 19 Januari 2011).

Belonio, A. T., Rice Husk Gas Stove Handbook, Appropriate Technology Center, Department of Agriculture Engineering and Environmental Management, Collage of Agriculture, Central Philippine University: Iloilo City, Philippines, 2005.

Dewi, R. G., Indonesian Position on Bioenergy and Bioreneweble, The Global Sustainable Bioenergy (GSB) Convention for The Asia -
Oceania Region, Kuala Lumpur, 14-16 Juni 2010.

ESDM, Handbook of Energy \& Economic Statistics of Indonesia, $7^{\text {th }}$ Eds., Departemen Energi dan Sumber Daya Mineral: Jakarta, 2010; hlm. 17-33.

Higman, C.; van der Burgt, M., Gasification, 2nd Eds, Gulf Professional Publishing: Burlington, USA, 2011.

Mukunda, H. S., Dassapa, S.; Paul, P. J.; Rajan, N. K. S.; Yagnaraman, M.; Kumar, D. R.; Deogaonkar, M., Gasifier stove-science, technology and field outreach, Current Science, 2010, 98(5), 627-638.

Panwar, N. L., Design and performance evaluation of energy efficient biomass gasifier based cookstove on multi fuels, Mitigation and Adaptation Strategies for Global Change, 2009, 14(7), 627-633.

Rajvanshi, A. K., Biomass Gasification, dalam Alternative Energy in Agriculture, Vol. 2, CRC Press: Boco Raton Florida, 1986, hlm. 83-102.

Reed, T. B.; Anselmo, E.; Kircher, K., Testing \& Modeling the Wood-Gas Turbo Stove, Progress in Thermochemical Biomass Conversion Conference, Tyrol, Austria, 17-22 September 2000 .

Reed, T. B.; Larson, R., A wood-gas stove for developing countries, Energy for Sustainable Development, 1996, 3(2), 34-37.

Umogbai, V. I.; Orkuma, J. G., Development and evaluation of a biomass stove, Journal of Emerging Trends in Engineering and Applied Sciences, 2011, 2(3), 514-520.

Yuntenwi, E. A.; MacCarty, N.; Still, D.; Ertel, J., Laboratory study of the effects of moisture content on heat transfer and combustion efficiency of three biomass cook stoves, Energy for Sustainable Development, 2008, $12(2), 66-77$. 